\title{
Effectiveness of misoprostol for induction of first and early second trimester spontaneous miscarriages in parous women
}

\author{
Tamima Al-Dughaishi ${ }^{1}$, Amjad Hamed Al-Haddabi ${ }^{2}$, \\ Mussab Mubarak Hamed Al-Jabri², Vaidyanathan Gowri ${ }^{1 *}$
}

${ }^{1}$ Department of Obstetrics and Gynecology, ${ }^{2}$ College of Medicine, Sultan Qaboos University, Oman

Received: 25 June 2018

Accepted: 08 September 2018

*Correspondence:

Dr. Vaidyanathan Gowri,

E-mail: gowrie61@ hotmail.com

Copyright: (c) the author(s), publisher and licensee Medip Academy. This is an open-access article distributed under the terms of the Creative Commons Attribution Non-Commercial License, which permits unrestricted non-commercial use, distribution, and reproduction in any medium, provided the original work is properly cited.

\begin{abstract}
Background: Medical termination of missed miscarriage and incomplete miscarriage with misoprostol, are an alternative to surgical evacuation (dilatation and curettage). This study aimed to evaluate the effectiveness of misoprostol in highly parous woman for incomplete and missed miscarriage.

Methods: This was a retrospective study was conducted in two different time lines (2010 and 2014). All patients admitted to the Sultan Qaboos University hospital, Muscat, Oman, for the management of first-trimester miscarriages (missed and incomplete types) during the study period were included. Some women were moved to dilation and curettage even after misoprostol. The effect of gravidity and parity on those women in whom misoprostol was not effective was studied.

Results: The overall success rate of misoprostol for the management was $62.14 \%$ in 2010 and $53.8 \% 2014$. In nulliparous woman the success rate of misoprostol was slightly higher than parous women. There was no apparent effect of gravidity and parity of $\geq 5$ or $\geq 5$ on the success of misoprostol.

Conclusions: Misoprostol reduced the rate of surgical evacuation among the study subjects. In highly parous and multigravid women ( $\geq$ para 5 and gravida $\geq 5$ ) the success was not significantly different compared to less parous women.
\end{abstract}

Keywords: Dilation and curettage, First trimester pregnancy, Incomplete abortion, Miscarriage, Misoprostol

\section{INTRODUCTION}

Miscarriage is defined according to World Health Organization (WHO) as "the premature loss of a fetus up to 23 weeks of pregnancy and weighing up to $500 \mathrm{~g}$ ". It account for about $20 \%$ of total pregnancies and $80 \%$ out of them occur in the first 12 weeks of gestation. ${ }^{1}$ The actual prevalence of miscarriage is much higher because some patients biochemical pregnancies and miscarry and the rate of miscarriage can be upto $31 \% .^{2}$ The patients have three choices as a management: expectant, medical and surgical for incomplete miscarriage. The expectant management also called "conservative management" in which the patient decided to wait until the miscarriage completed naturally and the conception product get evacuated passively .Usually it is the favored choice when the uterus is small or when there is few amounts of remaining products. ${ }^{3}$ Surgical management has been gold standard in the past for incomplete and missed miscarriage but medical management with misoprostol has emerged in the last two decades after many trials.

Medical management is usually by misoprostol which is a prostaglandin E1 analogue, misoprostol. This drug was listed in the World health organization (WHO) model list of essential medicine 18th list in April 2013 as a drug used for management of incomplete miscarriage as well as for prevention of postpartum hemorrhage (WHO, 
2013). ${ }^{4}$ Misoprostol causes uterine contraction and therefore it facilitates the removal of remaining products of conception. The effect of misoprostol depends on the dose and the route of administration. ${ }^{5,6}$ There is a wide variation in efficacy rates in the management of miscarriage according to NICE guidelines, ranging from $13 \%$ to $96 \% .^{7}$ A recent metanalysis found complete evacuation rates ranging between $60 \%$ and $83 \%$ for missed miscarriage and $99 \%$ for incomplete miscarriage. ${ }^{8}$

Though there are many studies on doses, route of administration, combination with or without mifepristone, there are not many studies on the success rate of medical management in parous women. Hence it was decided to study the effect of misoprostol in parous women.

\section{METHODS}

This is a retrospective study conducted at Sultan Qaboos University Hospital (SQUH). Patients included are those who were admitted in Gynecology ward for management of first trimester miscarriage - missed miscarriage or incomplete miscarriage in the period between January to December 2010 and January to December 2014. All patients were suitable for either medical or surgical management. They were counselled on both methods and they chose either one of them. Those who chose expectant management were excluded from the study.

Ethical approval obtained from Medical Research and Ethics Committee of SQUH. Information was retrieved on maternal characteristic such as: age, gravidity, parity, abortion.

Index pregnancy details also were obtained like: gestational age which measured by ultrasound, weeks of gestation by last menstrual period (LMP), and uterine size. Statistical analysis was done on coded data using Statistical Package for the Social Sciences (SPSS) software. Data were categorized and analyzed using frequencies tables, pie charts as well as the comparisons were carried using the Pearson Chi-square test. Two different time lines were chosen as the protocol was standardized after 2010 but there was variation in the dosage of misoprostol used prior to that.

\section{RESULTS}

The results showed that there were 227 patients in 2010. Of the 227 there were 110 patients who took misoprostol only, 47 patients had $\mathrm{D}$ and $\mathrm{C}$ and 70 patients took misoprostol, but they ended up with $\mathrm{D}$ and $\mathrm{C}$ for various reasons. There were 184 in 2014 represented in, 71 of them took misoprostol only, 56 patients had $\mathrm{D}$ and $\mathrm{C}$ and 57 patients had misoprostol then turned to $\mathrm{D}$ and $\mathrm{C}$. the success rate of misoprostol in 2010 was $61.1 \%$ and in
2014 it was $55.47 \%$. The $\mathrm{z}$ score for the success rate in comparison of both years was 1.23. In 2010 there were 109 patients $(48.02 \%)$ with incomplete miscarriage and 118 patients $(51.98 \%)$ with missed miscarriage, but in 2014 there were 107 patients $(58.15 \%)$ with incomplete miscarriage and $77(41.85 \%)$ with missed miscarriage as shown in (Figure 1).

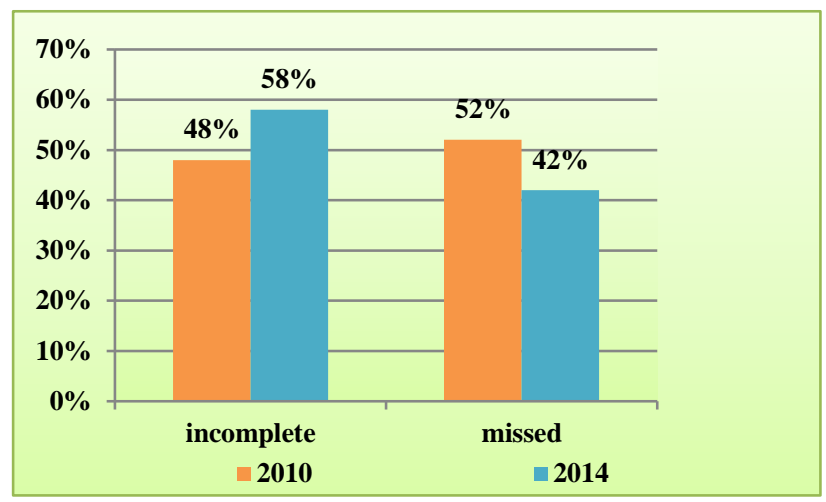

Figure 1: Percentage of missed and incomplete miscarriages in 2010 and 2014.

In 2010, the success rate of misoprostol at the age group $<=25$ year was $65.71 \%$, ages $26-35$ years. was $58.89 \%$ and age $>=36$ years was $61.82 \%$. In 2014 , the success rate of misoprostol at the age group $<=25$ years was $50.00 \%$, at the ages $26-35$ years was $58.82 \%$ and at the age $>=36$ years was $52.63 \%$ as shown in Table 1 .

Table 1: Success of misoprostol in 2010 and 2014.

\begin{tabular}{|lll|}
\hline & 2010 & 2014 \\
\hline 25 year & $65.71 \%$ & $50.00 \%$ \\
\hline$\geq 36$ year-35 year & $58.89 \%$ & $58.82 \%$ \\
\hline Average & $61.82 \%$ & $52.63 \%$ \\
\hline
\end{tabular}

In 2010, the success rate of misoprostol at (prima gravida) group was $74.36 \%$ and, in those patients, who had previous pregnancy had a success rate of $57.45 \%$. In 2014 the success rate of misoprostol for primi gravida was $59.38 \%$ and those patients who had previous pregnancy had a success rate of $54.17 \%$ as shown in (Table 2).

Table 2: Success rate of misoprostol in primigravida and multigravida women.

\begin{tabular}{|lll|}
\hline & 2010 & 2014 \\
\hline Primigravid women & $74.36 \%$ & $59.38 \%$ \\
\hline Multigravid women & $57.45 \%$ & $54.17 \%$ \\
\hline
\end{tabular}

The maximum parity, abortions and the dose of misoprostol needed are explained in Table 3. 
Table 3: Maximum parity and miscarriages in relation to the number of doses of misoprostol.

\begin{tabular}{|lllllll|}
\hline & 2010 & & & 2014 & Maximum & Mean \\
\hline Parity & Minimum & Maximum & Mean & Minimum & Mam & 2.49 \\
\hline Previous abortions & 0 & 12 & 2.72 & 0 & 12 & 0.88 \\
\hline Weeks of gestation & 0 & 5 & 0.67 & 0 & 22 & 11.57 \\
\hline Number of doses of misoprostol & 0 & 22 & 11.56 & 6 & 3 & 0.95 \\
\hline
\end{tabular}

Table 4: Success rate of misoprostol incomplete and missed abortion.

\begin{tabular}{|lll|} 
& 2010 & 2014 \\
\hline Incomplete & $70.0 \%$ & $51.50 \%$ \\
\hline Missed & $55.50 \%$ & $60.00 \%$ \\
\hline
\end{tabular}

The success rate of misoprostol at 2010 for both, incomplete and missed abortion were $70.0 \%$ and $55.5 \%$ respectively. The success rate of misoprostol at 2014 for incomplete miscarriage was $51.5 \%$ and for missed miscarriage was $60.0 \%$ as shown in Table 4.

Table 5: Gravidity and patients needing evacuation after misoprostol.

\begin{tabular}{|lll|}
\hline Moved to D and C & Gravidity $\leq 4$ & Gravidity $\geq 5$ \\
\hline Yes & $32.5 \%(80 / 246)$ & $29.7 \%(49 / 165)$ \\
\hline No & $67.5 \%(166 / 246)$ & $60.3 \%(116 / 165)$ \\
\hline P value & 0.620 & \\
\hline
\end{tabular}

The need for evacuation after misoprostol was analyzed in multigravida and multiparous women and it was not statistically significant (Table 5 and 6).

Table 6: Parity and patients needing evacuation after misoprostol.

\begin{tabular}{|lll|}
\hline Moved to D \& C & Parity $\leq 4$ & Parity $\geq 5$ \\
\hline Yes & $32.9 \%(109 / 331)$ & $25.0 \%(20 / 80)$ \\
\hline No & $67.1 \%(222 / 331)$ & $75.0 \%(60 / 80)$ \\
\hline P value & 0.216 & \\
\hline
\end{tabular}

\section{DISCUSSION}

All age groups in 2010 had a higher success rate than those in 2014 , this can be due to a slightly higher dose of used in 2010 than 2014 (Table 3). In both 2010 and 2014, primigravida group had higher success rate than those who had previous pregnancy, and this is comparable to the study done by El Kholi and Hefedab. ${ }^{9}$ Borgatta and Creinin commented that success rate is less in women of parity of more than three. ${ }^{10,11}$ Lefebvre et al also found the success rate more in nulliparous women for medical abortion. ${ }^{12}$

According to Spitz et al the success rate was less in women with previous elective termination of pregnancy but most of present study patients had previous spontaneous miscarriages and there was no significant variation in success with previous multiparty or multigravidity as per Table 5 and $6 .{ }^{13}$ Most of the studies quoted except the one by Kholi et al have been done with mifepristone and also for elective medical termination and not for pregnancy failure. In the study by Verma and Thakur only $5 \%$ women were more than gravida five whereas present study has more number of women in this group. ${ }^{14}$ It is a paradox that the same medication, misoprostol at lower dose is more effective in parous women than nulliparous women for labour induction at advanced pregnancy. ${ }^{15}$

There are not very many studies on misoprostol alone in the area of pregnancy failure and hence this may be useful information to counsel.

Funding: No funding sources

Conflict of interest: None declared

Ethical approval: The study was approved by the Institutional Ethics Committee

\section{REFERENCES}

1. Regan L, Rai R. Epidemiology and the medical causes of miscarriage. Baillieres Best Pract Res Clin Obstet Gynaecol. 2000;14(5):839-54.

2. Wilcox, A., Weinberg, C., O'Connor, J., Baird, D., Schlatterer, J., Canfield, R., Armstrong, E. and Nisula, B. Incidence of Early Loss of Pregnancy. New Eng J Med. 1988;319(4): 189-94.

3. Niinimäki M, Karinen P, Hartikainen AL, Pouta A. Treating miscarriages: a randomised study of costeffectiveness in medical or surgical choice. BJOG 2009;116(7):984-90.

4. WHO model list of essential medicine 18th Ed. Available

http://www.who.int/medicines/publications/essential medicines/18th_EML_Final_web_8Jul13.pdf.

5. Rausch M, Lorch S, Chung K, Frederick M, Zhang J, Barnhart K. A cost effectiveness analysis of surgical versus medical management of early pregnancy loss. Fertil Steril. 2012;97(2):355-360.

6. Tang J, Kapp N, Dragoman M, de Souza JP. WHO recommendations for misoprostol use for obstetric and gynaecologic indications. Int $\mathbf{J}$ Gynecol Obstet. 2013;121(2):186-9. 
7. National Institute for Health and Care Excellence. Ectopic Pregnancy and Miscarriage: Diagnosis and Initial Management in Early Pregnancy of Ectopic Pregnancy and Miscarriage (CG154). London: NICE; 2012.

8. Graziosi GC, Mol BW, Ankum WM, Bruinse HW. Management of early pregnancy loss. Int J Gynaecol Obstet 2004;86(3):337-46.

9. ELkholi DG, Hefedab MM. Potential predictors for successful misoprostol treatment for early pregnancy failure: Clinical and color Doppler imaging study Middle east. Fertilty Society J 2015;20(3): 144-53

10. Borgatta L, French A, Vragovic O, Burnhill MS. Early Medical Abortion with Methotrexate and Misoprostol: Outcomes and Satisfaction Among Women Aged 15-21 Years. J Ped Adole Gynecol. 2001;14(1):9-16.

11. Creinin MD, Vittinghoff E, Keder L, Darney PD, Tiller G. Methotrexate and misoprostol for early abortion: a multicenter trial. I. Safety and efficacy. Contracep. 1996;53(6):321-7.

12. Lefebvre P, Cotte M, Monniez N and Norel G.The role of parity in medical abortion up to 49 days of amenorrhoea. Europ J Contracep Reproduct Health Care. 2008;13(4):404-11,
13. Spitz IM, Bardin CW, Benton L, Robbins A. Early pregnancy termination with mifepristone and misoprostol in the United States. New Eng J Med. 1998;338(18):1241-7.

14. Verma M, Thakur V, Awasiya P. A comparative study of misoprostol versus surgical management of incomplete and missed miscarriage. International $\mathbf{J}$ Reproduct, Contracep, Obstet Gynecol. 2016;5(11):3654-8.

15. Tan TC, Yan SY, Chua TM, Biswas A, Chong YS. A randomised controlled trial of low-dose misoprostol and dinoprostone vaginal pessaries for cervical priming. BJOG: Int $\mathrm{J}$ Obstet Gynaecol. 2010;117(10):1270-7.

Cite this article as: Al-Dughaishi T, Al-Haddabi AH, Al-Jabri MMH, Gowri V. Effectiveness of misoprostol for induction of first and early second trimester spontaneous miscarriages in parous women. Int J Reprod Contracept Obstet Gynecol 2018;7:4512-5. 